\title{
Retraction Note: Prediction of aggregate modified index (AMI) using geomechanical properties of limestones
}

\author{
G. R. Khanlari ${ }^{1}$ - F. Naseri ${ }^{1}$ \\ Published online: 28 September 2021 \\ ○) Springer-Verlag GmbH Germany, part of Springer Nature 2021
}

Retraction Note to: Bulletin of Engineering Geology and the Environment (2018) 77:803-814 https://doi.org/10.1007/s10064-016-0984-1

The Editors-in-Chief have retracted this article because it was previously published by Khanlari et al. (2015). This article is therefore redundant.

None of the authors have responded to any correspondence from the editor/publisher about this retraction.

\section{Reference}

Khanlari G, Naseri F, Osman Pour A (2015) Introducing a new aggregates index (AI) using petrograghical and geomechanical properties (Case study: Hamedan province limestones). Sci Quarterly J Iranian Association Eng Geology 8(Number 1 \& 2):51-66

G. R. Khanlari

Khanlari_Reza@yahoo.com

1 Department of Geology, Faculty of Sciences, University, Mahdieh Ave, 65175-38695 Bu-Ali SinaHamedan, Iran 